\title{
Advocacy for outpatient cardiac rehabilitation globally
}

\author{
Abraham Samuel Babu' ${ }^{1}$ Francisco Lopez-Jimenez ${ }^{2}$, Randal J. Thomas ${ }^{2}$, Wanrudee Isaranuwatchai ${ }^{3,4}$, \\ Artur Haddad Herdy ${ }^{5}$, Jeffrey S. Hoch ${ }^{3,4}$, Sherry L. Grace ${ }^{6,7^{*}}$ and in conjunction with the International Council of \\ Cardiovascular Prevention and Rehabilitation (ICCPR)
}

\begin{abstract}
Background: Cardiovascular diseases (CVD) are the leading cause of death globally. Cardiac rehabilitation (CR) is an evidence-based intervention recommended for patients with CVD, to prevent recurrent events and to improve quality of life. However, despite the proven benefits, only a small percentage of those would benefit from CR actually receive it worldwide.

This paper by the International Council of Cardiovascular Prevention and Rehabilitation forwards the groundwork for successful CR advocacy to achieve broader reimbursement, and hence implementation.

Methods: First, the results of the International Council's survey on national CR reimbursement policies by government and insurance companies are summarized. Second, a multi-faceted approach to CR advocacy is forwarded. Finally, as per the advocacy recommendations, the economic impact of CVD and the corresponding benefits of CR and its cost-effectiveness are summarized. This provides the case for $C R$ reimbursement advocacy.

Results: Thirty-one responses were received, from 25 different countries: 18 (58.1\%) were from high-income countries, 10 (32.4\%) from upper middle-income, and 3 (9.9\%) from lower middle-income countries. When asked who reimburses at least some portion of CR services in their country, 19 (61.3\%) reported the government, 17 (54.8 \%) reported patients pay out-of-pocket, 16 (51.6\%) reported insurance companies, 12 (38.7\%) reported that it is shared between the patient and another source, and 7 (22.6\%) reported another source.

Conclusions: Many patients pay out-of-pocket for CR. CR reimbursement around the world is inconsistent and insufficient. Advocacy campaigns forwarding the CR cause, supported by the relevant literature, enlisting sources of support in a unified manner with an organized plan, are needed, and must be pursued persistently.
\end{abstract}

Keywords: Cardiovascular disease, Reimbursement, Cardiac rehabilitation, Insurance

Abbreviations: CR, Cardiac rehabilitation; CVD, Cardiovascular disease; DALYs, Disability-adjusted life years; ICCPR, International Council for Cardiovascular Prevention and Rehabilitation; SD, Standard deviation; WHO, World Health Organization

\section{Background}

Cardiovascular disease (CVD) is the leading cause of death globally, [1] and the burden of CVD is growing [2]. Consequently, CVD accounts for $10 \%$ of disabilityadjusted life years (DALYs) lost worldwide; $10 \%$ of

\footnotetext{
* Correspondence: sgrace@yorku.ca

${ }^{6}$ School of Kinesiology and Health Science, York University, Bethune 368, York University, 4700 Keele Street, Toronto M3J 1P3, ON, Canada

${ }^{7}$ Toronto Western Hospital, GoodLife Fitness Cardiovascular Rehabilitation Unit, University Health Network, Toronto, ON, Canada

Full list of author information is available at the end of the article
}

DALYs lost in low and middle-income countries, and $18 \%$ of DALYs lost in high-income countries [3, 4]. According to the Global Burden of Disease Study, CVD was the leading cause of disability-adjusted life years lost in 2010 [4]. In the same year, years lived with disability due to ischemic heart disease was 8795 for all ages, or 128 per 100,000 [5].

Cardiac rehabilitation (CR) is an outpatient chronic disease management program for the secondary prevention of CVD. The World Health Organization has defined $C R$ as the "sum of activities required to influence 
favorably the underlying cause of the disease, as well as the best possible physical, mental and social conditions, so that they may by their own efforts, preserve or resume when lost, as normal a place as possible in the society" [6]. The core components of $\mathrm{CR}$ include baseline patient assessment, nutritional counseling, risk factor modification, psychosocial interventions, physical activity counseling and exercise training [7-13].

The substantive clinical benefits of CR have recently been summarized [14, 15]. In brief, in high-income countries, CR is shown to reduce morbidity and mortality by $25 \%$ [15]. In low and middle-income countries, CR participation is associated with significant improvements in lipids, body mass index, blood pressure, as well as quality of life, and functional capacity $[14,16]$.

Unfortunately, CR is grossly under-developed around the globe [17]. While the reasons are multi-factorial, arguably the chief reason is lack of service reimbursement. Accordingly, the International Council of Cardiovascular Prevention and Rehabilitation (www.globalcardiacrehab.com; Fig. 1) set out to develop a resource for CR professionals and associations to advocate for $\mathrm{CR}$ reimbursement. This conceptual paper first describes the scope of the problem of low use of CR and reimbursement. Results from a survey undertaken by the International Council regarding $C R$ reimbursement by government and insurance companies in various regions of the globe are presented. Second, a 6step approach to advocating for CR is provided. The approach starts with demonstration of the scale of the CVD problem, and then supporting evidence. Accordingly, the paper concludes with this needed information, summarizing the economic impact of CVD and the economic benefits of CR, to support CR advocacy efforts.

\section{Significant Gap in cardiac rehabilitation availability and participation}

$\mathrm{CR}$ services are scarce. Specifically, $\mathrm{CR}$ is available in only $38.8 \%$ countries worldwide: $68.0 \%$ of high-income, $28.2 \%$ of middle-income and $8.3 \%$ of low-income countries [17]. Where CR programs are available, it has been seen that most, if not all countries have insufficient capacity to treat indicated patients [17]. The number of CR programs per inhabitant (which we refer to as CR density), is a crude estimate of the number of patients who might

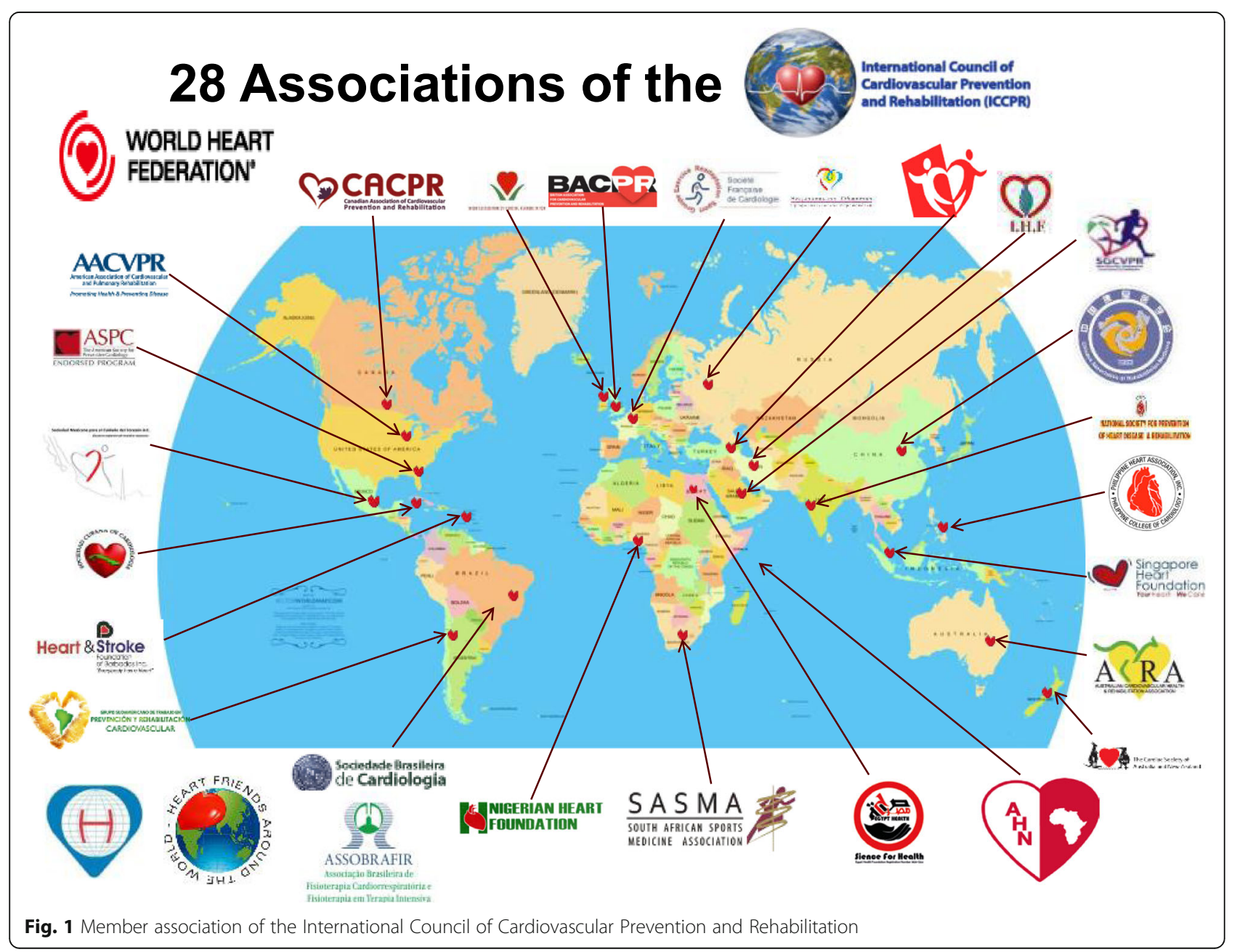


have access to CR in each country [18]. Based on national and regional surveys in high-income countries, CR density ranges from one program per 100,000 to one program per 300,000 inhabitants [19-21]. In middle-income countries, CR density ranges from 0.9 to 6.4 million inhabitants per program [19]. No low-income country is known to have more than 1 CR program [17].

Accordingly, participation in CR is also low [22-24]. For example, the European Action on Secondary Prevention by Intervention to Reduce Events III Survey showed that only $36.5 \%$ of 8845 indicated patients from 22 European countries (19 of which were high-income) attended CR [25]. Findings from the European CR Inventory Survey revealed that CR enrolment rates $>50 \%$ were seen in only $3(10.7 \%)$ countries while rates $<30 \%$ were reported in 15 (53.6\%) of the 28 countries [26]. In the United States, the largest study ever on CR utilization among 601,099 Medicare beneficiaries eligible for CR demonstrated that only $12.2 \%$ participated [27]. The international Stabilisation of Atherosclerotic Plaque by Initiation of Darapladib Therapy trial revealed that majority of the participants $(65 \%)$ had never participated in CR [28]. The International Council on Cardiovascular Prevention and Rehabilitation argues that lack of $\mathrm{CR}$ provision, and hence patient access, is a direct function of lack of reimbursement.

\section{Reimbursement of cardiac rehabilitation}

Coverage of services is tantamount to increasing delivery. Unfortunately, very little is known about reimbursement for $\mathrm{CR}$ services around the globe. In order to better understand this issue, several authors (AB, FL, SG) designed an online survey assessing $C R$ reimbursement on behalf of the International Council of Cardiovascular Prevention and Rehabilitation. Items assessed the nature of coverage for $\mathrm{CR}$ services by government and healthcare insurance companies, using a similar approach as described previously $[18,29]$. The survey was reviewed by experts in the area of CR. Then, it was emailed to the member organizations of the International Council of Cardiovascular Prevention and Rehabilitation (Fig. 1), who were asked to complete it and forward it to their CR colleagues from different countries (i.e., snowball sampling). Respondents were asked to contact the top 3 health insurers in their country on the basis of premiums collected and to consult official government statistics or academic publications to provide accurate reimbursement data.

This was a cross-sectional study. Thirty-one responses were received, representing 25 countries (or $34 \%$ of all 83 countries that offer CR globally) [17]. Fifty-eight percent of respondents were from high-income, $32 \%$ upper middle-income, and $10 \%$ were from lower middle-income countries. It must be conceded that the generalizability of responses is unknown, the number of responses was low, and the source of estimates is unknown (e.g., whether government statistics were accessed and the number of insurance providers successfully contacted). Therefore the results presented herein, while providing initial valuable information on CR reimbursement internationally, should be interpreted with caution. Moreover, results should not be considered representative of low-income countries.

When asked who reimburses $\mathrm{CR}$ in their country (respondents were asked to check all that apply), $61 \%$ reported the government, $55 \%$ reported patients pay out-of-pocket, $52 \%$ reported insurance companies, $39 \%$ reported that it is shared between the patient and another source, and $23 \%$ reported another source (e.g., public hospitals only, subsidized by Heart Foundation, insurance coverage by some companies only).

\section{Government reimbursement}

Government-reimbursed indications for $\mathrm{CR}$ were most often myocardial infarction, coronary artery bypass graft surgery and percutaneous coronary intervention (all $100 \%)$, followed by heart failure, valve surgery/procedures, and heart transplant (all $87 \%$ ), as well as stable angina (73\%), and rhythm devices (60\%). Respondents reported that a mean of 32.0 (standard deviation; SD = 12.9) CR sessions were covered by government for each patient, and that a mean of $91.5 \%(\mathrm{SD}=19.2 \%)$ of the total $\mathrm{CR}$ program cost was covered by government (i.e., no deductible or out-of-pocket fee). Almost one-fifth of respondents reported that the government limits the components of CR covered.

Aspects of CR which were reimbursed most often included supervised exercise (93\%), followed by dietary counselling, mental health/psychological support, smoking cessation, hypertension control and hyperlipidemia control (all $80 \%$ ), education (73\%), weight control (67\%), and return-to-work/occupational therapy (53\%). When asked whether the government specified the type of professional treating the cardiac patient to be eligible for CR funding, over half responded yes; the type of professional was most often a cardiologist, nurse or physiotherapist (each $99 \%$ ).

\section{Insurance company reimbursement}

Reimbursed indications for CR were synonymous with those reported with government funding. Respondents reported that mean of $22.2(\mathrm{SD}=15.4)$ sessions were covered, and that mean of $48.3 \%(\mathrm{SD}=50.5 \%)$ of the total $\mathrm{CR}$ program cost was covered by private healthcare insurance. Where the patient paid some money toward $\mathrm{CR}$, the average cost was USD $\$ 17.5(\mathrm{SD}=6.9)$ /session or USD \$345.0 (SD = 38.2)/program. Some respondents commented that the insurance companies only covered physical activity and exercise training. 


\section{Advocacy for cardiac rehabilitation}

Advocacy is "the act or process of supporting a cause or proposal" [30]. It involves the art of communication by an individual or group, often on behalf of others, with the purpose of supporting an idea or cause. Effective advocates influence public policy, laws and budgets by using facts, personal stories, their relationships, the media, and messaging to educate government officials, policy-makers and the general public about the importance and the potential impact of the idea or cause they are supporting. When applied in the healthcare setting, advocacy is carried out at various levels by a variety of people-patients, providers, healthcare advocacy groups, healthcare industry representatives, and others. Healthcare advocacy work is important because the voice of advocates can help shape and implement important and beneficial healthcare policies and practices.

Policy-makers face a challenging task of decisionmaking while being inundated with a large amount of data, opinions, and requests. They must maintain a delicate balance between what is best for individuals and what is best for society. Effective advocates assist policymakers in these balancing efforts by helping to clarify and simplify the complexities of issues that surround a given idea or cause. Advocates generally speak with a unique degree of authenticity, as they bring personal stories and experiences with them that link them to the cause for which they advocate.

The cause for reimbursement and delivery of CR can be bolstered by common advocacy pathways. These including the upcoming Sustainable Development Goals, in particular the third proposed goal regarding health, specifically reducing premature mortality from noncommunicable diseases through prevention and treatment by one-third by 2030, as well as achieving universal health coverage to promote access to essential medicines $[31,32]$. These current windows of opportunity represent areas where CR advocacy could find synergy and hence greater success.

\section{Cardiac rehabilitation-specific advocacy}

Despite the large amount of evidence [15, 33, 34] showing the benefits of CR services to eligible patients, advocacy has been challenging. $\mathrm{CR}$ services are beneficial, yet relatively simple and low-cost, when compared to other services in the field of cardiovascular medicine. Arguably then, CR services have not generally attracted much attention from administrators, clinicians, and even patients, given the "low-tech", lower budget nature of CR services.

In the past three decades, CR professionals from various countries around the world have been involved as advocates on behalf of their patients, helping to shape and implement important healthcare policies for the provision of $\mathrm{CR}$ to eligible patients. Advocacy messaging has been primarily based on what is in the best interests of eligible patients-to promote the delivery of CR services to the large number of individuals who are eligible for such services each year.

Components of a successful CR advocacy program are multi-faceted, and include the following:

a) A just "cause": The strength of an advocacy program is dependent largely on the evidence that $\mathrm{CR}$ services provide strong, positive benefits for individuals and/or society.

b) Publications to support the cause: CR advocacy is strengthened by research studies and other scholarly works that have been published in respected, peer-reviewed scientific publications.

c) Key sources of support: Advocacy is dependent on key voices of support from the general population, key national healthcare leaders, key healthcare organizations, key healthcare policy-makers (i.e., someone in an influential position to bring about a solution or with a personal connection to the issue), and high visibility public figures who are "champions" for the cause, giving a face and a sense of personal impact to the cause.

d) Unified support: Successful CR advocacy depends on unified support-either for clinical practice or policy reasons-from leading professional organizations in the field of cardiology.

e) Organized plan: An organized plan is critically important to CR advocacy efforts; a plan that includes goals, strategies and tactics to address scientific, policy, financial, and communication needs, among other things.

f) Persistence: $\mathrm{CR}$ advocacy efforts take time and patience, given the resistance to change that exists at all levels of the decision-making process, from patients and providers, to policy-makers and healthcare leaders.

Communications methods are critically important in the work of advocacy towards CR. The key to coverage negotiations is identifying the needs and benefits to the patient, government and/or insurance companies. By providing an explanation of the services and benefits of $C R$ for insured clients, coverage may be considered by governments and insurance companies. Key points for communication in a CR advocacy campaign are presented in Table 1.

In countries where advocacy work has not yet resulted in insurance coverage policies for $\mathrm{CR}$, healthcare systems could consider alternative $\mathrm{CR}$ models at least for the short-term, including home-based CR, mobile technology tools, and other forms of lower-cost delivery models (e.g., outdoor Asociacion Cardiovascular Centrooccidental CR program in Barquisimeto, Venezuela). 
Table 1 Communication methods for a cardiac rehabilitation advocacy campaign

\begin{tabular}{ll}
\hline Method of communication & Description \\
\hline Key messages & $\begin{array}{l}\text { This includes important messages } \\
\text { that should be repeated often, and } \\
\text { be easy to understand in order to } \\
\text { gain support }\end{array}$
\end{tabular}

Letter-writing and/or phone call campaigns

This includes campaigns towards policy makers which are wellcontrolled and coordinated.
Meetings with policy-makers, either in private or in public

Media messaging on the issue (including social media and websites)

This provides prime opportunity to personalize the cause they are supporting by sharing their perspective, story, and passion.

This includes sharing stories on CR topics (e.g., patient's personal story of triumphs or struggles with heart disease, new findings of scientific significance to the field, or expert opinions about urgent public health concerns or heart-related illnesses of public figures) through various media sources

Abbreviation: $C R$ cardiac rehabilitation
Table 2 Summary of success stories from four countries across the globe

\begin{tabular}{|c|c|c|}
\hline Country & What did they do? & What did they achieve? \\
\hline Iran & $\begin{array}{l}\text { Developed a CR } \\
\text { research center } \\
\text { Enhanced research } \\
\text { Discussion and seminars } \\
\text { with policy-makers \& } \\
\text { insurance companies }\end{array}$ & $\begin{array}{l}\text { Directive from the } \\
\text { Ministry of Health that } \\
\text { all components of CR } \\
\text { will be reimbursed by } \\
\text { insurance companies } \\
\text { Improved CR attendance }\end{array}$ \\
\hline Qatar & $\begin{array}{l}\text { Developed clinical } \\
\text { services and formed a CR } \\
\text { planning committee } \\
\text { Collaborating with other } \\
\text { organizations for phase } \\
3 \text { CR }\end{array}$ & $\begin{array}{l}\text { Formed the working } \\
\text { group of Qatar } \\
\text { Association for } \\
\text { Cardiovascular Prevention } \\
\text { and Rehabilitation } \\
\text { Improved CR referrals }\end{array}$ \\
\hline $\begin{array}{l}\text { United } \\
\text { Kingdom }\end{array}$ & $\begin{array}{l}\text { Evidence-based } \\
\text { campaigning for } \\
\text { reimbursement } \\
\text { Emphasis from national } \\
\text { guidelines on CR and } \\
\text { formation of standards } \\
\text { for delivery of CR }\end{array}$ & $\begin{array}{l}\text { Created a National } \\
\text { Commissioning Guide } \\
\text { and Tool-kit to fund CR } \\
\text { Improved CR referrals }\end{array}$ \\
\hline $\begin{array}{l}\text { United States } \\
\text { of America }\end{array}$ & $\begin{array}{l}\text { AACVPR developed } \\
\text { performance } \\
\text { measures for CR } \\
\text { Provided evidence-based } \\
\text { campaigns from } \\
\text { long-term studies } \\
\text { Conducted government } \\
\text { sponsored projects } \\
\text { showing cost- } \\
\text { effectiveness of CR }\end{array}$ & $\begin{array}{l}\text { Developed performance } \\
\text { measures of CR } \\
\text { HF included under } \\
\text { indications for CR referral } \\
\text { State health plans to } \\
\text { cover essential health } \\
\text { benefits related to CR }\end{array}$ \\
\hline
\end{tabular}

Abbreviations: $C R$ cardiac rehabilitation, AACVPR American Association of Cardiovascular and Pulmonary Rehabilitation, $H F$ heart failure

to mortality, $€ 18,873,665,000$ due to morbidity, and $€ 43,560,202,000$ in informal care. Overall, the cost of CVD to EU was approximately $€ 196$ billion annually in 2009 [38] which is a steep increase from $€ 169$ in 2003 [39].

A similar picture emerges in North America. In the United States, CVD also accounts for a large share of total spending. The average annual cost per person attributable to CVD is $\$ 4734$ (2005 American dollars) [40]. By 2030, $40.5 \%$ of the American population is projected to have some form of CVD, and total direct costs are projected to reach more than $\$ 800$ billion in 2008 American dollars (from $\$ 273$ billion in 2010). The indirect costs due to productivity loss are estimated to increase to $\$ 276$ billion in 2030 .

In low and middle-income countries, the burden of CVD is of epidemic proportions [41, 42]. Using economic growth models, which assess the effect of chronic diseases on national income, the estimated losses because of coronary heart disease, stroke, and diabetes ranged from $\$ 20$ to 30 million in Ethiopia and Vietnam to almost $\$ 1$ billion in larger countries such as India and China [41]. In the scenario with no support to reduce risk of chronic diseases, an estimated $\$ 84$ billion of national income (American dollars) will be lost to heart disease, stroke, and diabetes alone in 23 selected low and middle-income countries between health care costs were estimated at $€ 26,963,326,000$ due
In the European Union, CVD was estimated to cost over $€ 106,156,940,0002009$ for health care-specific costs which included five categories: primary care, outpatient care, emergency, inpatient care, and medications. Non-

CR professionals have begun advocating for broader CR delivery and reimbursement. Relenting efforts have United States and United Kingdom. A summary of these success stories is given in Table 2, and include CR supportive funding policy and program initiation in

\section{Economic impact of cardiovascular disease}

as mentioned in the introduction, CVD is also associated with a significant economic burden. Focusing on cost (i.e., costs associated with hospital inpat care, outpatient physician visits, and medications), CVD has the highest total costs of any health condition [37] 
2006 and 2015, namely China, India, Russia, Brazil, Indonesia, Mexico, Turkey, Pakistan, Thailand, Bangladesh, Ukraine, Egypt, Argentina, Burma, Iran, Poland, South Africa, Philippines, Colombia, Vietnam, Nigeria, Ethiopia, and Democratic Republic of the Congo [41].

From an individual's perspective, CVD poses a great economic burden on the family and the community. This is not only due to productivity loss, but also care costs. Studies indicate that CVD drives approximately $10 \%$ of affected families into poverty in a low and middle-income country like India [16]. Moreover, due to disability caused by CVD, individuals may require assistance with activities of daily living (which costs money), as well as financial support if their productivity decreases.

\section{Economic impact of cardiac rehabilitation}

Overall, CR has consistently shown to be either cost-saving or to be cost-effective regardless of the country where it was examined, the perspective used, the costs included, and the year when it was analyzed [33]. In fact, European studies have demonstrated that CR may actually be a costsaving intervention [25]. A cost-effectiveness analysis using pooled data from randomized clinical trials and cohorts demonstrated that CR would cost $\$ 4950$ per year of life saved [26]. Systematic reviews of all the available evidence show savings of $\$ 12,000 / C R$ patient over 5 years, to $\$ 9200$ per quality-adjusted life year [33]. To put this in perspective, Table 3 shows cost-effectiveness values for common treatments and procedures for the secondary prevention of CVD.

Because CR has been demonstrated to decrease total mortality, cardiovascular mortality, cardiovascular events, procedures, and re-hospitalizations, and has shown to improve quality of life, the denominator in the costeffectiveness equation is generally as good, or better, than many other cardiovascular interventions [33, 34, 43, 44]. In addition to these benefits, CR has also been reported to increase return to work [45]. Those values are presumably stable across countries and geographic regions, as the benefit of CR is expected to be similar (as long as the program is of good quality and similar to the programs used in the primary studies). On the contrary, the cost component of a cost-effectiveness analysis will vary from country to country, because the cost of major components of CR can be significantly different across geographic regions. For example, major components like the salary for nurses, physicians, and other healthcare providers are significantly higher in high-income countries when compared to low

Table 3 Cost-effectiveness estimations for different interventions in patients with coronary artery disease

\begin{tabular}{|c|c|c|c|}
\hline Author (year) & Intervention & Patient population & Estimated savings \\
\hline Ades et al. (1997) [46] & $\begin{array}{l}\text { CR versus with other post-Ml treatment } \\
\text { interventions }\end{array}$ & Post $\mathrm{Ml}$ or revascularization & $\begin{array}{l}\text { CR was found to result in savings } \\
\text { of } 2,130 \$ / Y L S \text { in } 1980 \text {, which was } \\
\text { projected to be } 4,950 \$ / Y L S \text { for } \\
1995\end{array}$ \\
\hline Johanneson et al. (1997) [47] & Statins (i.e., Simvastatin) versus no statins & Angina or Ml & $\begin{array}{l}\text { Simvastatin use resulted in } \$ 3,800 \\
\text { to } \$ 27,400 \text { cost per year of life } \\
\text { gained }\end{array}$ \\
\hline Cleland et al. (1997) [48] & $\begin{array}{l}\text { CABG + Medical therapy + aspirin versus } \\
\text { CABG + medical therapy + aspirin }+ \text { statin } \\
\text { versus medical+aspirin+statin versus } \\
\text { medical + aspirin }\end{array}$ & Chronic stable angina & $\begin{array}{l}\$ 36,709, \$ 55,156 \text { and } \$ 23,730 \text { per } \\
\text { QALY for each comparison over } 5 \\
\text { years }\end{array}$ \\
\hline Chan et al. (2007) [49] & High intensity versus low intensity statin & $\begin{array}{l}\text { Acute coronary syndrome, } \\
\text { Chronic coronary disease }\end{array}$ & $\begin{array}{l}\text { From } \$ 20,000 \text { to } \$ 35,000 \text { if cost } \\
\text { difference of statins is between } \\
\$ 2 \text { and } \$ 3.50 \\
\text { From } \$ 70,000 \text { to } \$ 125,000 \text { if cost } \\
\text { difference of statins is between } \\
\$ 2 \text { and } \$ 3.50\end{array}$ \\
\hline Dendale et al. (2008) [50] & $C R$ versus no $C R$ & Post PCl & $\begin{array}{l}\text { Reduction in total health care } \\
\text { costs with CR (€4,862/patient } \\
\text { versus } € 5,498 \text { Euro/patient) }\end{array}$ \\
\hline Weinbtraub et al. (2008) [51] $]^{a}$ & $\begin{array}{l}\mathrm{PCl} \text { and medical therapy versus Medical } \\
\text { therapy alone }\end{array}$ & Stable angina & $\begin{array}{l}\$ 168,000 \text { to } \$ 300,000 \text { per QALY } \\
\text { gained with } P C l\end{array}$ \\
\hline Wilson et al. (2012) [52] & $\begin{array}{l}\text { Smoking cessation with varenicline plus } \\
\text { counseling versus counseling only }\end{array}$ & CVD & $\begin{array}{l}\text { Savings ranging from } € 5151 \text { - } \\
€ 6120 \text { per QALY gained }\end{array}$ \\
\hline Smith et al. (2013) [53] & $\begin{array}{l}\text { Implantable cardiac defibrillator versus no } \\
\text { defibrillator }\end{array}$ & $\begin{array}{l}\text { Primary prevention of sudden death in } \\
\text { patients with left ventricular ejection } \\
\text { fraction }<40 \% \text { (ischemic and non- } \\
\text { ischemic) }\end{array}$ & $\begin{array}{l}€ 43,993 \text { per QALY gained } \\
\text { compared to no defibrillator }\end{array}$ \\
\hline
\end{tabular}

Abbreviations: $\$ / Y L S$ dollars per year of life saved, $C V D$ cardiovascular disease, $M I$ myocardial infarction, $P C I$ percutaneous coronary intervention, $Q A L Y$, qualityadjusted life year

${ }^{a}$ COURAGE (Clinical Outcomes Utilizing Revascularization and Aggressive druG Evaluations) trial 
and middle-income countries. Likewise, costs related to use of physical space and other costs related to the overall expenses of CR can also be significantly higher in a highincome country.

Therefore, as the measure of effectiveness is expected to be similar but costs are expected to be lower in low and middle-income countries, it is safe to assume that the estimates of cost-effectiveness for $\mathrm{CR}$ will probably be more favorable in low and middle-income countries. For example, if the overall cost of CR in a low and middle-income country is only one-half of the total cost in a high-income country, the already favorable estimates for cost-effectiveness may actually become cost-saving. This suggests that in a low and middleincome country, not providing $\mathrm{CR}$ might actually be more expensive to payers and to society than providing $\mathrm{CR}$. This can occur because the lack of a medical intervention (i.e., CR) meant to prevent adverse events and procedures would lead to major expenses, making the lack of CR more expensive than offering it itself. We do concede however that more data in this area is needed.

\section{Conclusions}

The need for CR has been established, and the economic benefits of $\mathrm{CR}$ provision have been demonstrated. Given the evidence of CR benefits for patient health and vocational outcomes, greater provision of these services through coverage may result in fewer recurrent cardiac events and associated hospitalizations, fewer revascularization procedures, as well as greater return-to-work and productivity. Given that CR is cost-effective, greater provision of such programs may be of significant economic benefit to government, insurance companies, the private sector and individuals.

It is imperative to advocate for reimbursement of CR services so that availability and affordability for patients will be greatly increased. An ancillary consequence will be that healthcare providers will be motivated to train and work in the field of CR, which will also enable greater implementation. It is incumbent upon CR associations to advocate for CR coverage, using the strategies forwarded herein.

\section{Additional file}

Additional file 1: Success stories. (DOCX $23 \mathrm{~kb}$ )

Additional file 2: Cardiac rehabilitation pamphlet. (PDF $1.09 \mathrm{mb}$ )

Additional file 3: Cardiac rehabilitation advocacy tool kit. (PDF 229 kb)

\section{Acknowledgements}

We gratefully acknowledge the following collaborators for sharing CR advocacy success stories: John Buckley, PhD, Theodoros Papasavvas, MSc, RPT; Karen Liu, RN, MS; Masoumeh Sadeghi, MD, and Zahra Kasaei, MD. We also acknowledge Nizal Sarrafzadegan, MD for providing substantive input on the outline; and Raquel Marinho, MSc, for administration and analysis of the $C R$ reimbursement survey.
Funding

None.

Availability of data and materials

The dataset analysed in the current study available from the corresponding author on reasonable request.

\section{Authors' contributions}

$A B, F L$ and SLG conceived of the work and designed the reimbursement survey. $\mathrm{WI}, \mathrm{HJ}$ and $\mathrm{FLJ}$ drafted the economic and cost sections. SLG drafted the sections on CR availability, benefits and reimbursement. RT drafted the section on advocacy and associated tables. $A B$ drafted the introduction and was responsible for referencing. $\mathrm{AH}$ drafted content related to the role of professional associations and governments in advocating for CR. All authors contributed to the development and revision of this manuscript and have approved the final submission.

\section{Authors' information}

$\mathrm{FL}$ is the Chair, International Committee, American Association of Cardiovascular and Pulmonary Rehabilitation (AACVPR).

RLT is the Vice-Chair, Clinical Cardiology Council, American Heart Association (AHA).

SLG is the Secretary of the International Council for Cardiovascular Prevention and Rehabilitation (ICCPR)

\section{Competing interests}

The authors declare that they have no competing interests.

\section{Consent for publication}

Not applicable.

Ethics approval and consent to participate

Not applicable.

\section{Author details}

${ }^{1}$ Department of Physiotherapy, School of Allied Health Sciences, Manipal University, Manipal 576104, Karnataka, India. ${ }^{2}$ Preventive Cardiology Program, Division of Cardiovascular Diseases, Mayo Clinic, Rochester, MN, USA. ${ }^{3}$ Centre for Excellence in Economic Analysis Research, Li Ka Shing Knowledge Institute, St. Michael's Hospital, 30 Bond Street, Toronto M5B 1 W8, ON, Canada. ${ }^{4}$ Institute of Health Policy, Management and Evaluation, University of Toronto, 155 College Street, Toronto M5T 3 M7, ON, Canada. Institute of Cardiology of Santa Catarina, Universidade e do Sul de Santa Catarina, Palhoça, Brazil. 'SChool of Kinesiology and Health Science, York University, Bethune 368, York University, 4700 Keele Street, Toronto M3J 1P3, ON, Canada. ${ }^{7}$ Toronto Western Hospital, GoodLife Fitness Cardiovascular Rehabilitation Unit, University Health Network, Toronto, ON, Canada.

Received: 27 October 2015 Accepted: 11 August 2016

Published online: 06 September 2016

\section{References}

1. World Health Organization; World Heart Federation; World Stroke Organization. Global atlas on CVD prevention and control. Geneva: WHO; 2011. http://www.who.int/cardiovascular_diseases/publications/atlas_cvd/ en/. Accessed 24 Sept 2015.

2. Bloom DE, Cafiero, ET, Jané-Llopis E, Abrahams-Gessel S, Bloom, LR, Fathima, S, et al. The World Economic Forum and Harvard School of Public Health. The global economic burden of non-communicable diseases. 2011. http://www3.weforum.org/ docs/WEF_Harvard_HE_GlobalEconomicBurdenNonCommunicableDiseases_2011. pdf. Accessed 24 Sept 2015

3. World Health Organization. The global burden of disease: 2004 update. http://www.who.int/healthinfo/global_burden_disease/2004_report_update/ en/.Accessed 29 Sept 2015

4. Murray CJ, Vos T, Lozano R, Naghavi M, Flaxman AD, Michaud C, et al. Disability-adjusted life years (DALYS) for 291 diseases and injuries in 21 regions, 1990-2010: a systematic analysis for the Global Burden of Disease Study 2010. Lancet. 2012;380:2197-223.

5. Vos T, Flaxman AD, Naghavi M, Lozano R, Michaud C, Ezzati M, et al. Years lived with disability (YLDs) for 1160 sequelae of 289 diseases and injuries 
1990-2010: a systematic analysis for the Global Burden of Disease Study 2010. Lancet. 2012;380:2163-96.

6. World Health Organization. Rehabilitation after cardiovascular disease with special emphasis on developing countries. WHO Technical Report Series No. 831. Geneva: WHO; 1993. http://apps.who.int/iris/bitstream/10665/38455/1/ WHO_TRS_831.pdf Accessed 28 Sept 2015.

7. Balady GJ, Williams MA, Ades PA, Bittner V, Comoss P, Foody JM, et al. Core Components of Cardiac Rehabilitation/Secondary Prevention Programs: 2007 Update. Circulation. 2007;115:2675-82.

8. American Association of Cardiovascular and Pulmonary Rehabilitation. Guidelines for Cardiac Rehabilitation and Secondary Prevention Programs. 5th ed. Human Kinetics: USA; 2013.

9. Buckley JP, Furze G, Doherty P, Speck L, Connolly S, Hinton S, et al. British Association of Cardiovascular Prevention and Rehabilitation scientific statement: British standards and core components for cardiovascular disease prevention and rehabilitation. Heart. 2013;99:1069-71.

10. Woodruffe S, Neubeck L, Clark RA, Gray K, Ferry C, Finan J, et al. Australian Cardiovascular Health and Rehabilitation Association (ACRA) Core Components of Cardiovascular Disease Secondary Prevention and Cardiac Rehabilitation 2014. Heart Lung Circ. 2015;24:430-41.

11. Piepoli MF, Corrà U, Adamopoulos S, Benzer W, Bjarnason-Wehrens B, Cupples M, et al. Secondary prevention in the clinical management of patients with cardiovascular diseases. Core components, standards and outcome measures for referral and delivery: a policy statement from the cardiac rehabilitation section of the European Association for Cardiovascular Prevention \& Rehabilitation. Endorsed by the Committee for Practice Guidelines of the European Society of Cardiology. Eur J Prev Cardiol. 2014;21:664-81.

12. Pavy $B$, lliou MC, Vergès-Patois $B$, Brion $R$, Monpère $C$, Carré $F$, et al. Exercise, Rehabilitation Sport Group (GERS); French Society of Cardiology. French Society of Cardiology guidelines for cardiac rehabilitation in adults. Arch Cardiovasc Dis. 2012;105:309-28.

13. Grace SL, Warburton DER, Stone JA, Sanderson B, Oldridge N, Jones J, et al. International charter on cardiovascular prevention and rehabilitation: A call for action. J Cardiopulm Rehabil Prev. 2013;33:128-31.

14. Turk-Adawi K, Grace SL. Narrative review comparing the benefits of, participation cardiac rehabilitation in high-, middle- and low-income countries. Heart Lung Circ. 2015;24:510-20.

15. Anderson L, Taylor RS. Cardiac rehabilitation for people with heart disease: an overview of Cochrane systematic reviews. Cochrane Database Syst Rev. 2014;12:CD011273

16. Thakur JS, Prinja S, Garg C, Mendis S, Menabde N. Social and economic implications of non-communicable diseases in India. Indian J Community Med. 2011;36(suppl):S13-22.

17. Turk-Adawi K, Sarrafzadegan N, Grace SL. Global availability of cardiac rehabilitation. Nat Rev Cardiol. 2014;11:586-96.

18. Anchique Santos CV, Lopez-Jimenez F, Benaim B, Burdiat G, Fernandez Coronado R, Gonzalez G, et al. Cardiac rehabilitation in Latin America. Prog Cardiovasc Dis. 2014;57:268-75.

19. Cortes-Bergoderi M, Lopez-Jimenez F, Herdy AH, Zeballos C, Anchique C, Santibañez C, et al. Availability and characteristics of cardiovascular rehabilitation programs in South America. J Cardiopulm Rehabil Prev. 2013;33:33-41.

20. Tramarin R, Ambrosetti M, De Feo S, Piepoli M, Riccio C. Griffo R; ISYDE-208 Investigators of the Italian Association for Cardiovascular Prevention, Rehabilitation and Prevention. The Italian Survey on Cardiac Rehabilitation2008 (ISYDE-2008). Part 3. National availability and organization of cardiac rehabilitation facilities. Official report of the Italian Association for Cardiovascular Prevention, Rehabilitation and Epidemiology (IACPR-GICR). Monaldi Arch Chest Dis. 2008;70:175-205.

21. Curnier DY, Savage PD, Ades PA. Geographic distribution of cardiac rehabilitation programs in the United States. J Cardiopulm Rehabil. 2005;25:80-4.

22. Suaya J, Shepard D, Normand S, Ades P, Prottas J, Stason W. Use of cardiac rehabilitation by Medicare beneficiaries after myocardial infarction or coronary bypass surgery. Circulation. 2007;116:1653-62

23. Kotseva K, Wood D, Backer GD, Bacquer DD. Use and effects of cardiac rehabilitation in patients with coronary heart disease: results from the EUROASPIRE III survey. Eur J Prev Cardiol. 2013;20:817-26.

24. Grace SL, Gravely-Witte S, Brual J, Monette G, Suskin N, Higginson L, et al. Contribution of patient and physician factors to cardiac rehabilitation enrollment: a prospective multilevel study. Eur J Cardiovasc Prev Rehabil. 2008:15:548-56
25. Levin LA, Perk J, Hedback B. Cardiac rehabilitation-a cost analysis. J Inten Med. 1991;230:427-34.

26. Bjarnason- Wehrens B, McGee H, Zwisler AD, Piepoli M, Benzer W, Schmid JP, et al. Cardiac rehabilitation in Europe: Results from the European cardiac rehabilitation inventory survey. Eur J Cardiovasc Prev Rehabil. 2010;17:410-8.

27. Suaya JA, Stason WB, Ades PA, Normand S-LT, Shepard DS. Cardiac rehabilitation and survival in older coronary patients. J Am Coll Cardiol. 2009;54:25-33.

28. Stewart R, Held C, Brown R, Vedin O, Hagstrom E, Lonn E, et al. Physical activity in patients with stable coronary heart disease: An international perspective. Eur Heart J. 2013;34:3286-93.

29. Thirapatarapong W, Thomas RJ, Pack Q, Sharma S, Squires RW. Commercial insurance coverage for outpatient cardiac rehabilitation in patients with heart failure in the United States. J Cardiopulm Rehabil Prev. 2014;34:386-9.

30. Merrian Webster. http://www.merriam-webster.com/dictionary/advocacy Accessed 24 Sept 2015.

31. Zoghbi WA, Duncan T, Antman E, Barbosa M, Champagne B, Chen D, et al. Sustainable development goals and the future of cardiovascular health: a statement from the Global Cardiovascular Disease Taskforce. Glob Heart. 2014;9:273-4.

32. United Nations General Assembly. Open working group on Sustainable Developmental Goals. Geneva; 2014. https://sustainabledevelopment.un.org/ sdgsproposal Accessed 26 Sept 2015

33. Wong WP, Feng J, Pwee KH, Lim J. A systematic review of economic evaluations of cardiac rehabilitation. BMC Health Serv Res. 2012;12:243.

34. Oldridge $N$. Exercise-based cardiac rehabilitation in patients with coronary heart disease: meta-analysis outcomes revisited. Future Cardiol. 2012;8:729-51.

35. American Association for Cardiovascular and Pulmonary Rehabilitation. https://www.aacvpr.org/Advocacy. Accessed 24 Sept 2015

36. World Heart Federation. http://www.world-heart-federation.org/what-wedo/advocacy/advocacy-toolkit/Accessed 24 Sept 2015

37. Public Health Agency of Canada. Economic burden of illness in Canada, 20052008. Ministry of Health, 2014. http://www.phac-aspc.gc.ca/publicat/ebic-femc/ 2005-2008/assets/pdf/ebic-femc-2005-2008-eng.pdf. Accessed 24 Sept 2015

38. Nichols M, Townsend N, Luengo-Fernandez R, Leal J, Gray A, Scarborough P, Rayner M. European cardiovascular disease statistics. Sophia Antipolis: European Heart Network, Brussels, European Society of Cardiology; 2010.

39. Leal J, Luengo-Fernández R, Gray A, Petersen S, Rayner M. Economic burden of cardiovascular diseases in the enlarged European Union. Eur Heart J. 2006;27:1610-9.

40. Trogdon JG, Finkelstein EA, Nwaise IA, Tangka FK, Orenstein D. The economic burden of chronic cardiovascular disease for major insurers. Health Promot Pract. 2007:8:234-42.

41. Abegunde DO, Mathers CD, Adam T, Ortegon M, Strong K. The burden and costs of chronic diseases in low-income and middle-income countries. Lancet. 2007;370:1929-38.

42. Gaziano TA. Reducing the growing burden of cardiovascular disease in the developing world. Health Aff (Millwood). 2007;26:13-24.

43. Sloan FA, Detsky AS, Kaplan RM, Dranove D, Weinstein MC, Pauly MV, et al. Valuing Health Care: Costs, Benefits, and Effectiveness of Pharmaceuticals and Other Medical Technologies. Sloan: Cambridge University Press; 1996.

44. Dunlay SM, Pack QR, Thomas RJ, Killian JM, Roger VL. Participation in cardiac rehabilitation, readmissions, and death after acute myocardial infarction. Am J Med. 2014;127:538-46.

45. Engblom E, Korpilahti K, Hämäläinen $H$, Rönnemaa T, Puukka P. Quality of life and return to work 5 years after coronary artery bypass surgery. Longterm results of cardiac rehabilitation. J Cardiopulm Rehabil. 1997;17:29-36.

46. Ades PA, Pashkow FJ, Nestor JR. Cost-effectiveness of cardiac rehabilitation after myocardial infarction. J Cardiopulm Rehabil Prev. 1997;17:222-31.

47. Johannesson M, Jonsson B, Kjekshus J, Olsson AG, Pedersen TR, Wedel H. Cost effectiveness of simvastatin treatment to lower cholesterol levels in patients with coronary heart disease. Scandinavian Simvastatin Survival Study Group. N Engl J Med. 1997;336:332-6.

48. Cleland JG, Walker A. Is medical treatment for angina the most costeffective option? Eur Heart J. 1997;18(Suppl B):B35-42.

49. Chan PS, Nallamothu BK, Gurm HS, Hayward RA, Vijan S. Incremental benefit and cost-effectiveness of high-dose statin therapy in high-risk patients with coronary artery disease. Circulation. 2007;115:2398-409.

50. Dendale P, Hansen D, Berger J, Lamotte M. Long-term cost-benefit ratio of cardiac rehabilitation after percutaneous coronary intervention. Acta Cardiol. 2008:63:451-6.

51. Weintraub WS, Boden WE, Zhang Z, et al. Cost-effectiveness of percutaneous coronary intervention in optimally treated stable coronary patients. Circ Cardiovasc Qual Outcomes. 2008;1:12-20. 
52. Wilson K, Hettle R, Marbaix S, Diaz Cerezo S, Ines M, Santoni L, et al. An economic evaluation based on a randomized placebo-controlled trial of varenicline in smokers with cardiovascular disease: results for Belgium, Spain, Portugal, and Italy. Eur J Prev Cardiol. 2012;19:1173-83.

53. Smith $T$, Jordaens $L$, Theuns DA, van Dessel PF, Wilde AA, Hunink MG. The cost-effectiveness of primary prophylactic implantable defibrillator therapy in patients with ischaemic or non-ischaemic heart disease: a European analysis. Eur Heart J. 2013;34:211-9.

Submit your next manuscript to BioMed Central and we will help you at every step:

- We accept pre-submission inquiries

- Our selector tool helps you to find the most relevant journal

- We provide round the clock customer support

- Convenient online submission

- Thorough peer review

- Inclusion in PubMed and all major indexing services

- Maximum visibility for your research

Submit your manuscript at www.biomedcentral.com/submit 